\title{
Régimen constitucional colombiano, su historia y desarrollo
}

MARCO ANDRÉS GUTIÉRREZ GUERRERO

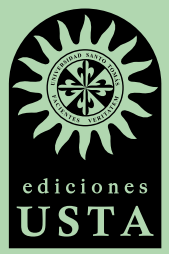



Régimen constitucional colombiano, su historia y desarrollo 



\section{Régimen constitucional colombiano, su historia y desarrollo}

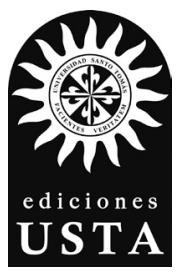




\section{Gutiérrez Guerrero, Marco Andrés}

Régimen constitucional colombiano, su historia y desarrollo / Marco Gutiérrez - Bogotá: Universidad Santo Tomás, 2016.

122 páginas, ilustraciones, gráficas.

ISBN 978-958-631-941-6

1. Derecho constitucional -- Colombia 2. Reformas constitucionales -- Colombia 3.

Derechos civiles - Colombia -- Historia 4. Derecho constitucional -- Historia I. Universidad Santo Tomás (Colombia).

CDD 342.9861

Co-BoUST

C Marco Andrés Gutiérrez Guerrero

(c) Universidad Santo Tomás

Ediciones USTA

Carrera 9 No.51-11

Edificio Luis J. Torres sótano 1

Bogotá, D. C., Colombia

Teléfonos: (+571) 5878797, ext. 2991

editorial@usantotomas.edu.co

http://ediciones.usta.edu.co

Dirección editorial: Matilde Salazar Ospina

Coordinación de libros: Karen Grisales

Asistente editorial: Andrés Felipe Andrade

Diagramación: María Paula Berón R.

Corrección de estilo: Ángela Guerra

ISBN: 978-958-631-941-6

Primera edición: 2016

Se prohíbe la reproducción total o parcial de esta obra, por cualquier medio, sin la autorización expresa del titular de los derechos. 
$\begin{array}{ll}\text { Presentación } & 9\end{array}$

$\begin{array}{ll}\text { Introducción } & 11\end{array}$

Régimen constitucional colombiano: reseña histórica

del constitucionalismo colombiano 11

Primer periodo (1819-1830) 13

La declaración de independencia y génesis del Estado colombiano $\quad 13$

La Constitución de 1811

$\begin{array}{ll}\text { Infografía } 1 & 15\end{array}$

La Constitución de la provincia de Cundinamarca 15

DE LA FORMA DE GOBIERNO Y SUS BASES

DE LA RELIGIÓN

DE LA CORONA

DE LA REPRESENTACIÓN NACIONAL

DEL PODER EJECUTIVO

DEL PODER LEGISLATIVO

DEL PODER JUDICIAL

DE LAS ELECCIONES

DE LA FUERZA ARMADA

DEL TESORO NACIONAL

DE LA INSTRUCCIÓN PÚBLICA

DE LOS DERECHOS DEL HOMBRE Y DEL CIUDADANO

DE LOS DEBERES DEL CIUDADANO

DISPOSICIONES GENERALES 


\section{Periodo transitorio (1830)}

Infografía 2

La Constitución de la Gran Colombia, 1830

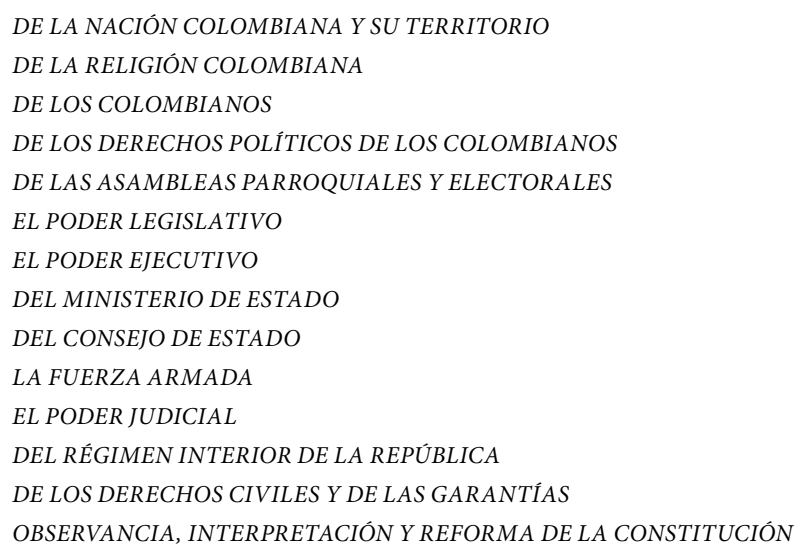

Constitucionalismo colombiano (1832-1991)

Constitución de 1832 y la Convención Constituyente, orígenes contexto histórico y aportes

Constitución de la República de la Nueva Granada, 1832

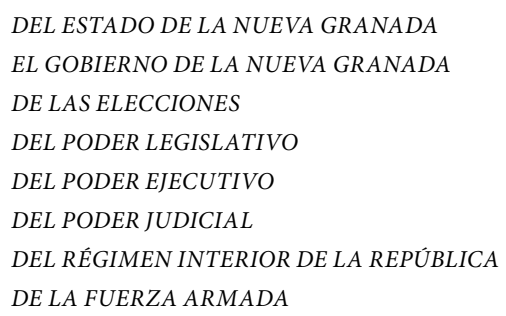

Infografía 4

Reforma a la Constitución de la República de la Nueva Granada, 1843

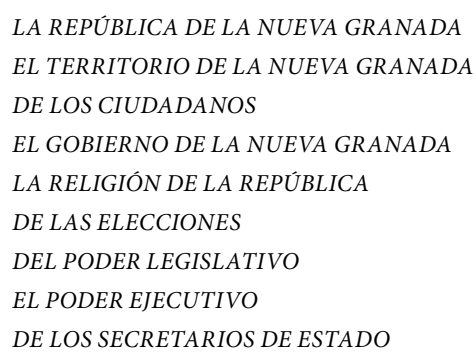


DEL PODER JUDICIAL

EL RÉGIMEN POLÍTICO DE LAS PROVINCIAS CANTONES Y DISTRITOS PARROQUIALES

LA RESPONSABILIDAD DE LOS EMPLEADOS PÚBLICOS, Y DE LOS JUICIOS

QUE SE SIGUEN ANTE EL SENADO

LA INTERPRETACIÓN O REFORMA DE LA CONSTITUCIÓN

Constitución Política de 1853, el origen federal en Colombia, orígenes contexto histórico y aportes

Infografía 5

Reforma a la Constitución de la República de la Nueva Granada, 1843

REPÚBLICA DE LA NUEVA GRANADA Y DE LOS GRANADINOS

GOBIERNO DE LA REPÚBLICA

DE LAS ELECCIONES

DEL PODER LEGISLATIVO

EL PODER EJECUTIVO

DEL PODER JUDICIAL

EL RÉGIMEN MUNICIPAL

Constitución Política de 1858, antecedentes y naturaleza

Reforma a la Constitución de la República de la Nueva Granada, 1843

DE LOS BIENES Y CARGAS DE LA CONFEDERACIÓN

DEL GOBIERNO DE LA CONFEDERACIÓN

PODER LEGISLATIVO

DE LA FORMACIÓN DE LAS LEYES

DEL PODER EJECUTIVO DE LA CONFEDERACIÓN

DEL PODER JUDICIAL

DEL MINISTERIO PÚBLICO

DE LOS DERECHOS INDIVIDUALES

ELECCIONES

DISPOSICIONES VARIAS

REFORMA CONSTITUCIONAL

Constitución Política de 1863, los Estados Unidos de Colombia, orígenes contexto histórico y aportes

La Constitución de los Estados Unidos de Colombia

ORIGEN

LA UNIÓN DE ESTADOS

BIENES Y CARGAS DE LA UNIÓN

COLOMBIANOS Y EXTRANJEROS

GOBIERNO GENERAL

PODER LEGISLATIVO

PODER EJECUTIVO

PODER JUDICIAL

MINISTERIO PÚBLICO 
RÉGIMEN DE ELECCIONES

DISPOSICIONES VARIAS

SISTEMA DE REFORMA

Constitución Política de 1886, la República de Colombia, orígenes y contexto histórico y aportes.

Infografía 7

Constitución Política de Colombia de 1886

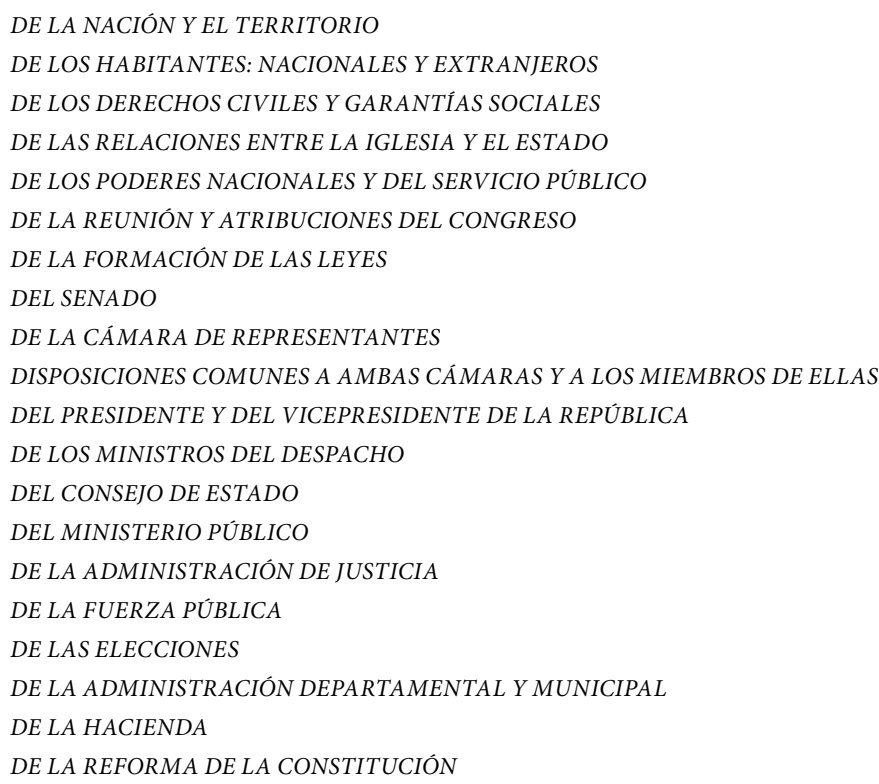

Referencias 


\section{Presentación}

El presente material de enseñanza tiene como fin ilustrar a los estudiantes y estudiosos de humanidades el desarrollo histórico de las instituciones constitucionales colombianas a lo largo de la experiencia republicana. A partir de este material el lector podrá identificar y reseñar las principales características y los primordiales rasgos de cada periodo histórico.

El desarrollo jurídico-político de Colombia desde el mismo grito emancipador ha sido matizado por diversas formas gubernamentales que se han apoyado sobre la base republicana, características que le dan a nuestro país una innegable condición de Estado demócrata y pluralista ampliamente reconocida por el concierto internacional. Así, este estudio pretende describir estas fibras íntimas de la historia constitucional colombiana con el ánimo inequívoco de ilustrar de forma dinámica y precisa cada momento dentro de nuestra historia, desde los albores de la república, pasando por el Estado federal colombiano, la república centralista, las hegemonías partidistas, hasta la definitiva transición al Estado Social de Derecho.

En este sentido, este trabajo pretende convertirse en una útil herramienta de consulta. Ella está dotada de información eficiente para absolver todo tipo de dudas concernientes a la evolución histórica del Estado colombiano, de donde surgirán respuestas frente a dudas trascendentales con relación a las modificaciones de las formas estatales. 



\section{Introducción}

\section{Régimen constitucional colombiano: reseña histórica del constitucionalismo colombiano}

La historia constitucional de la República de Colombia ha estado enmarcada dentro de un escenario fluctuante en el que se han experimentado diversos esquemas de orden estatal. Estos esquemas han variado desde la simplicidad propia de las nuevas repúblicas post independentistas de América Latina, hasta complejos ordenamientos mixtos de índole federal y unitario. Por ello, dentro del esquema metodológico proponemos tres grandes periodos a saber; 1 . Primer periodo (1819-1830) entendido como la génesis misma del Estado colombiano, 2. Periodo transitorio (1830) entendido como la transición institucional entre el sistema de integración multinacional y la consolidación del Estado colombiano; 3. Periodo constitucional (1832-1991) entendido como el período de cambios constitucionales de la república colombiana. 



\section{Primer periodo (1819-1830)}

La gran incertidumbre constitucional; primeras aproximaciones dogmáticas:

\section{La declaración de independencia y génesis del Estado colombiano}

El fenómeno independentista que se expandió vertiginosamente por toda América Latina, y que trajo como resultado la inexcusable emancipación de estas naciones de la corona española, no solo introdujo el cambio natural propio de la independencia sino que también implantó la necesidad de consolidar unos fenómenos jurídicos-políticos capaces de mitigar las nuevas necesidades de los estados nacientes. Así las cosas, el actual territorio ocupado por las repúblicas de Colombia y Venezuela encaró el rumbo a su madurez estatal el día 7 de agosto de 1819 con la icónica batalla de Boyacá, la cual no sólo significó la derrota de las tropas españolas del Brigadier José María Barreiro, sino el trascendental acto emancipador de la campaña libertadora. Tras la llegada victoriosa del ejército de Bolívar a la ciudad de Santafé de Bogotá se organizó el desenlace de la campaña definitiva que culminaría con los actos de proclamación en Angostura, donde en llamado extraordinario el Congreso en pleno eligió unánimemente a Simón Bolívar como primer Presidente. Así pues, los territorios de Colombia y Venezuela se organizaron como entidades territoriales individuales que serían gobernadas y regidas por un gobernador de manera transitoria, mientras el Congreso se volviera a reunir nuevamente en la ciudad de Cúcuta, para organizar definitivamente el Estado a través de un modelo constitucional. 
Ahora bien, sin duda la referencia histórica de la Constitución de Cúcuta nos ubica en un escenario privilegiado de la historia jurídico-política de nuestro país, por ser esta una indiscutible fuente normativa de independencia, y sobre todo de reafirmación soberana de la identidad del pueblo colombiano. Sin embargo, es fundamental resaltar que previa a esta Constitución (que trataremos en detalle), existieron unas expresiones constitucionales que merecen toda nuestra atención. Así las cosas, este primer capítulo estará dedicado a estudiar la totalidad de estas manifestaciones constitucionales, las cuales estuvieron marcadas por una gran incertidumbre institucional, pues para dicho momento histórico la claridad de la independencia del virreinato español era aún difusa, y por ende, la calidad soberana de estos textos estuvo gobernada por la confusión, y en muchos casos por la zozobra misma del momento histórico.

\section{La Constitución de 1811}

De cara a los convulsionados eventos que sacudieron la normalidad de la vida cotidiana del Virreinato de la Nueva Granada, aquel 20 de julio de 1810, las provincias del territorio granadino abogaron a través de diversos movimientos independentistas la promulgación de un sistema federal (similar al establecido en los Estados Unidos de América) y, como consecuencia, se originó la Federación de las Provincias Unidas de la Nueva Granada. Allí se anexaron los territorios de Pamplona, Cartagena, Antioquia, Neiva y Tunja. Por su parte, la provincia de Cundinamarca - cuya importancia política y administrativa era imprescindible-, decidió hacerse a un lado de esta iniciativa y, por el contrario, resolvió adherir a la Provincia de Mariquita, recia defensora de la concepción estatal unitaria. Este bloque provincial causó serías tensiones entre las provincias de la Nueva Granada.

Ahora bien, la provincia de Cundinamarca suscribió su constitución el día 4 de abril de 1811, su texto fue redactado por Jorge Tadeo Lozano, quien se sirvió del modelo norteamericano, destacando que el texto contenía principios dogmáticos republicanos, pero a su turno se servía también de principios monárquicos. 


\section{Infografía 1}

\section{La Constitución de la provincia de Cundinamarca}

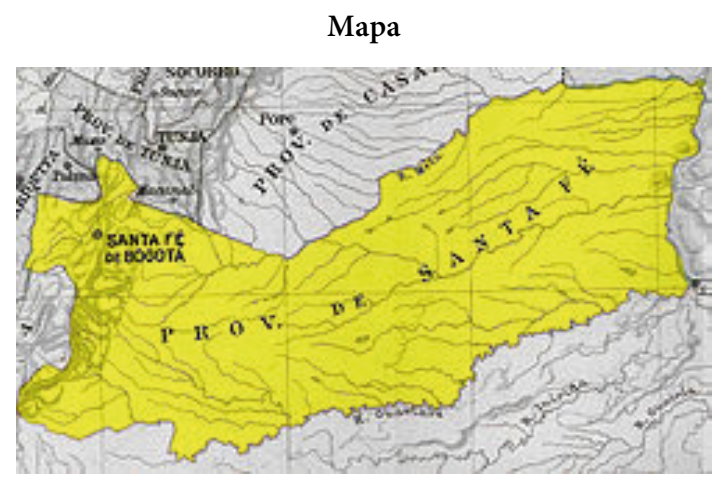

Símbolos
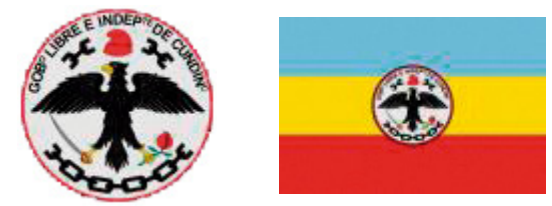

\section{DE LA FORMA DE GOBIERNO Y SUS BASES}

Se proclamaba como un Estado soberano, ratifica su reconocimiento a Fernando VII como autoridad suprema. Reconoce y profesa la religión católica, apostólica romana como la única verdadera. Los Poderes Ejecutivo, Legislativo y Judicial se ejercitarán con independencia unos de otros; aunque con el derecho de objetar el Poder Ejecutivo lo que estime conveniente a las libertades del legislador en su caso y lugar. El ejercicio del Poder Ejecutivo corresponde al Rey, auxiliado de sus ministros. El Cuerpo Legislativo nombrará un presidente particular del Cuerpo mismo, con el título de prefecto de la legislatura, un designado para sus ausencias, y un Secretario, 
dando noticia de estos nombramientos al Gobierno. El Poder Judicial correspondía a los tribunales de la provincia.

\section{DE LA RELIGIÓN}

La religión católica, apostólica, romana es la religión de este Estado. No se permitirá otro culto público ni privado, y ella será la única que podrá subsistir a expensas de las contribuciones de la provincia y caudales destinados a este efecto, conforme a las leyes que en materia gobiernan.

\section{DE LA CORONA}

La provincia de Cundinamarca se erige en monarquía constitucional para que el Rey la gobierne según las leyes, moderando su autoridad por la Representación Nacional que en esta Constitución se expresa y determina.

El Rey en su ingreso al trono jurará sostener y cumplir esta Constitución como base fundamental del Gobierno, y cualquier infracción que haga sin la previa revisión y consentimiento de la Representación Nacional deberá mirarse como una renuncia de la Corona. No será lícito al Rey renunciar en favor de ningún tercero, sea el que fuere, y en el caso de dimitir la Corona, lo hará en manos de la Representación Nacional, para que ésta haga lo que conviniere al bien de la Provincia en uso de la soberanía que la corresponde. El Rey no podrá contraer matrimonio sin el consentimiento y aprobación de la Representación Nacional de esta provincia, y si lo hiciere, deberá mirarse como una renuncia de la Corona. De haberlo ya hecho se reserva el pueblo el derecho y facultad de resolver si le es o no perjudicial la alianza que hubiere contraído.

\section{DE LA REPRESENTACIÓN NACIONAL}

La Representación Nacional se compone del Presidente y Vicepresidente, Senado de Censura, dos consejeros del Poder Ejecutivo; los miembros del Legislativo y dos tribunales que ejercen el Poder Judicial. Cuando el Rey está presente, y en ejercicio de sus funciones, el Presidente, los consejeros del Poder Ejecutivo y el Vicepresidente, que es Presidente del Senado de Censura, concurren como miembros de la Representación 
Nacional. El Rey es Presidente nato de la Representación Nacional, y en su defecto, el Presidente nombrado por el pueblo.

\section{DEL PODER EJECUTIVO}

El ejercicio del Poder Ejecutivo de esa Provincia corresponde al Rey. Cuando el Rey ejercite el Poder Ejecutivo es bajo la responsabilidad de sus ministros, los cuales no quedarán cubiertos de esta responsabilidad sino dando inmediatamente cuenta al Senado de las providencias que el Rey quiera tomar o tome, contrarias a la Constitución del Estado.

\section{DEL PODER LEGISLATIVO}

El ejercicio del Poder Legislativo corresponde a los miembros nombrados por el pueblo para este efecto. El número de estos miembros dependerá del censo de la población, el de diez y nueve. Se calcula por cómputo el más aproximado al de esta provincia en ciento noventa mil habitantes, y se señala por cada diez mil un individuo en la Legislatura. La renovación se hará sacando la mitad de los miembros más antiguos, de suerte que a excepción de este primer año, que saldrán por sorteo, siempre se verifique que cada miembro sirva durante dos años.

\section{DEL PODER JUDICIAL}

El Poder Judicial examina las diferencias que se suscitan entre los ciudadanos, tiene la autoridad de fijar sus derechos, juzgar sus demandas y querellas, y aplicar las penas establecidas por las leyes a los infractores de ellas.

El uso ordinario de estos juicios es lo que propiamente se conoce como Poder Judicial. El ejercicio de este poder, como parte de la Representación Nacional, corresponde a los tribunales superiores de la provincia. Los jueces de la primera instancia, los inferiores, y las municipalidades que existen o aquellos que de nuevo se establezcan para facilitar la administración de justicia, y cuiden de la policía, no tienen parte en la Representación Nacional. 


\section{DE LAS ELECCIONES}

El día 3 de noviembre el alcalde de cada parroquia de las comprendidas en esta provincia convocará todos los años a todos sus parroquianos, para el nombramiento de electores de la parroquia. Al Colegio Electoral corresponde la elección de representante o representantes y suplentes de la provincia para el Congreso General del Reino.

\section{DE LA FUERZA ARMADA}

El objeto de la fuerza armada es el de defender al Estado de todo ataque y toda irrupción enemiga, evitar conmociones y desórdenes en lo interior, y celar el cumplimiento de las leyes. Todo ciudadano es soldado nato de la patria mientras que sea capaz de llevar las armas, sin distinción de clase, estado o condición; y nadie puede eximirse del servicio militar en las graves urgencias del Estado cuando peligra la patria.

\section{DEL TESORO NACIONAL}

Todo ciudadano tiene obligación de contribuir para el culto divino y la subsistencia para los Ministros del Santuario, para los gastos del Estado, la defensa y seguridad de la patria, el decoro y la permanencia de su Gobierno, la administración de justicia y la Representación Nacional. El Cuerpo Legislativo entre sus primeros cuidados tendrá en consideración la materia de impuestos y contribuciones, así como el arreglo general del Tesoro público de la provincia, para simplificar su cobranza y administración, trabajando principalmente en conciliar la riqueza del Estado con el mayor alivio de los pueblos.

\section{DE LA INSTRUCCIÓN PÚBLICA}

En todos los poblados deberán establecerse escuelas de primeras letras y dibujo. Estas deben dotarse competentemente a partir de los fondos de la respectiva región. Estas escuelas deben separarse en los dos sexos. Estas escuelas deben instruir para saber leer, escribir, dibujar, conocer los primeros elementos de la geometría, y antes que todo, la doctrina cristiana y las obligaciones y los derechos del ciudadano, conforme a la Constitución. 


\section{DE LOS DERECHOS DEL HOMBRE Y DEL CIUDADANO}

Los derechos del hombre en sociedad son la igualdad y libertad legales, la seguridad y la propiedad.

La libertad ha sido concedida al hombre, no para obrar indistintamente el bien o el mal, sino para obrar el bien por elección.

La libertad es la facultad que el hombre tiene de hacer todo lo que no sea en daño de tercero o en perjuicio de la sociedad.

El uso de la libertad está ceñido necesariamente a este principio inspirado por la naturaleza, sancionado por la ley y consagrado por la religión: "no hagas a otro lo que no quieres que se haga contigo".

La ley es la voluntad general explicada libremente por los votos del pueblo en su mayor número, o por medio de sus representantes legítimamente constituidos.

La igualdad consiste en que, siendo la ley una misma para todos, todos son iguales delante de la ley.

Nadie puede tener libertad, igualdad, seguridad y propiedad en sí mismo si no respeta la de los demás.

\section{DE LOS DEBERES DEL CIUDADANO}

La primera obligación del ciudadano mira a la conservación de la sociedad, y ésta exige que los que la componen conozcan y cumplan respectivamente sus deberes.

Estos están encerrados en la pureza de la religión y de las costumbres, en la observancia de la Constitución y el sometimiento a las leyes.

Es deber del ciudadano defender y servir a la sociedad, vivir sujeto a las leyes y respetar a los funcionarios públicos encargados mediata o inmediatamente de su establecimiento, ejecución y aplicación.

No es buen ciudadano el que no es buen hijo, buen padre, buen hermano, buen amigo o buen esposo.

No merece tampoco este nombre el que no observa religiosamente las leyes, el que por intrigas, cábalas y maquinaciones elude su cumplimiento, y el que sin justo motivo se excusa de servir a la Patria. 


\section{DISPOSICIONES GENERALES}

Toda ley dictada en perjuicio de la libertad, propiedad y seguridad del ciudadano, cuya promulgación se haya hecho en fuerza de una imperiosa necesidad de circunstancias, es esencialmente provisional, y sus efectos no deben extenderse por más tiempo que el de un año.

La ley supervigilará particularmente aquellas profesiones que interesan a las costumbres públicas, a la seguridad y sanidad de los ciudadanos.

La ley debe fijar recompensa para los inventores, y velar en la conservación de la propiedad exclusiva por tiempo señalado de su descubrimiento o de sus producciones. 